\title{
Chile
}

\section{Criação teatral no Chile nos ÚLTIMOS VINTE ANOS}

\author{
Eduardo Guerrero del Río - Universidad Finis Terrae
}

\begin{abstract}
Dentro dos estudos do teatro chileno do Século XX, são facilmente distinguíveis algumas etapas nas quais, tanto por motivos artísticos como de outra índole (políticos, sociais, econômicos, etc.), se manifestaram alguns fenômenos de interesse. Por exemplo, desde meados dos anos 80 em diante - sobretudo de 1985 a 1990 - surgiram em nosso país uma série de grupos independentes ou criadores que têm priorizado o espetáculo sobre a peça dramática (o texto). Assim, nomes tais como os de Alfredo Castro e o Teatro La Memoria, Mauricio Celedón e o Teatro del Silencio, Ramón Griffero e o Teatro Fin de Siglo, Andrés Pérez e o Gran Circo Teatro, Horacio Videla e o Teatro Provisorio, o grupo La Troppa, Alejandro Goic e o grupo El Bufón Negro, Willy Semler, Juan Edmundo González, Rodrigo Pérez, para citar os mais importantes, são representativos do "renascer" do teatro chileno.

Estes nomes ajudaram a revitalizar nossa cena, sob o paradigma de um conceito esquecido por muitos anos: experimentação, risco, busca de novas linguagens.
\end{abstract}

\section{Instâncias relevantes}

Antes de abordar com maior amplitude as diretrizes fundamentais desta nova geração de teatristas chilenos, mencionaremos, ainda que seja de forma sucinta, como se configurou nosso teatro desde a década dos anos $40 \mathrm{em}$ diante, já que é factível considerar algumas instâncias estruturantes.

Em primeiro lugar, a criação dos teatros universitários - em 1941 o Teatro Experimentalde la Universidad de Chilee, dois anos depois, o Teatro de Ensayo da Universidad Católica - deram lugar, nos anos 50 e 60, fundamentalmente, a espetáculos que "revolucionaram" o ambiente cultural de Santiago del Chile

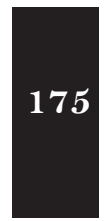


(entre os postulados programáticos propostos por esses teatro se encontravam: conhecimento da dramaturgia universal contemporânea, criação de escolas de teatro, educação do público e preocupação pelas linguagens da encenação). Com respeito a isso se observou que com os anos, houve um melhoramento gradual das técnicas de atuação, um manejo mais adequado dos instrumentos físicos (luz, som...), além da reunião de importantes dramaturgos chilenos que conformaram o que se chamou "geração dos anos 50 ou dos teatros universitários", sem dúvida - do ponto de vista da dramaturgia - a mais decisiva geração no teatro chileno de todos os tempos e, a nosso entender, não superada literariamente.

No contex to temporal, certos fatores externos possibilitaram a criação dos teatros universitarios, entre os quais não podemos deixar de assinalar as turnês da atriz catalã Margarita Xirgu, com repertório de Federico García Lorca, e o início em 1938 do período presidencial de Pedro Aguirre Cerda, com toda a importância dada às universidades, à classe média e, fundamentalmente, à educação.

Além disso, a dinâmica dos teatros universitários serviu de exemplo para que outros grupos nascessem - incluindo alguns nas províncias - e fomentaram uma atividade cênica com similares exigências. Assim, podemos reconhecer a existência do teatro independente, fenômeno útil de constatar, pois também dramaturgos da geração dos 50 se formaram neste ambiente. Entre eles, temos: Jorge Díaz, Luis Alberto Heiremans, Alejandro Sieveking, Sergio Vodanovic, Egon Wolff, como seus maiores expoentes.

Em segundo lugar, o golpe militar de 1973 não somente produziu uma ruptura em nossa institucionalidade e sistema democrático, como também no desenvolvimento artístico, fundamentalmente por causa da diáspora provocada pelo exílio, pela repressão sistemática exercida pelo estado ditatorial e pelas restrições às liberdades expressivas. Desta maneira, na década dos anos 70 , não se manifestou uma geração de dramaturgos de relevo em relação à mencionada anteriormente. $\mathrm{O}$ que se constituiu como uma expressão válida foi o trabalho da criação coletiva, com suas múltiplas facetas, devido ao seu caráter contestador ao regime militar. Assim, o teatro independente - subvencionado e não subvencionado - cumpriu um importante papel artístico e cultural em nosso país substituindo o predomínio dos teatros universitários nas décadas anteriores. Grupos como o Ictus, Imagen, Taller de Investigación Teatral (TIT), La Feria - para assinalar os de maior importância-, privilegiaram a criação coletiva - em suas diversas modalidades -, com o fim de concretizar desta forma seu trabalho cênico. Como exemplo, cabe mencionar 
que um dos motivos recorrentes de algumas destas criações, foi o trabalho, em peças como Pedro, Juan y Diego (Ictus e David Benavente), ¿Cuántos años tiene un día? (Ictus e Sergio Vodanovic), Tres Marías y una Rosa (TIT), Los payasos de la esperanza (TIT), El último tren (Imagen e Gustavo Meza), todas elas em um contexto de clara oposição à ditadura (em todo caso, às vezes uma oposição muito velada pelos problemas existentes com a censura). Um tema pendente que ainda precisa ser analisado pelos pesquisadores chilenos se refere à produção teatral chilena no exílio, pois de alguma forma isso completaria a visão deste período.

\section{Uma nova história}

Em termos gerais, nas décadas dos anos 80 e 90, e no correr desta década, pode-se vislumbrar algumas características predominantes:

1. Surgimento de autores dramáticos (sem conformar uma geração de dramaturgos) que evidenciam, através da linguagem, novas propostas cênicas, sempre tendo como referente inevitável a situação sócio-política imperante no Chile (época de ditadura e de democracia, posteriormente). Assim, dentro de sua diversidade dramatúrgica, principalmente os nomes de Juan Radrigán, Marco Antonio de la Parra, Ramón Griffero, Benjamín Galemiri, passaram a constituir os de maior renome.

2. Preponderância da imagem sobre a palavra com a incorporação de elementos cinematográficos, de coreografias e, mais que nada, de todas as linguagens comprometidas na encenação, o que Roland Barthes chamou "polifonia informacional" (música, iluminação, cenografia, gesto, figurino, som, maquiagem...). Isso se complementa com o aparecimento de diretores de grande criatividade e estilos próprios, como é o caso de Griffero, Castro, Semler, Pérez, González, Lorca, Goic, entre outros. Sobre isso, o crítico de teatro e pesquisador Juan Andrés Piña afirma que neste teatro "se pesquisa as distintas possibilidades do teatro como palco, como lugar de ação: a iluminação, os espaços físicos, o campo visual, a música, a justaposição de elementos cenográficos, os diversos estilos de atuação e a maquiagem, se convertem em recursos tão válidos como o diálogo falado”?

3. Preocupação tanto pelo teatro latino americano como pelo teatro europeu por causa dos paralelismos temáticos e pelas buscas formais comuns (no primeiro caso) e as possibilidades dos textos de permitir a elaboração de um discurso teatral no qual este adquire uma nova dimensão criativa (no segundo caso).

2Juan Andrés Piña:

Modos y temas del teatro chileno: la voz de los 80. Mimeografiado. 


\section{Urdimento}

${ }^{3}$ Alfonso de Toro: El 'nuevo' teatro latinoamericano $o$ la constitución de la postmodernidad espectacular. Mimeografiado.
4. Redescobrimento dos autores clássicos, a partir de uma perspectiva dupla: contemporaneidade do discurso textual e, no que diz respeito às encenações, o agilizar o discurso com o entrecruzamento das diversas linguagens da teatralidade. Isto possibilitou que o espectador conheça a dramaturgos que, em muitas ocasiões, são quase desconhecidos para a grande maioria, com o conseqüente "deslumbramento" ante textos que dizem muito mais que a atual escritura dramática.

5. Em muitas oportunidades, ante a escassez de textos nacionais ou por uma particular disposição da companhia, foram adaptados poemas, contos e inclusive romances, com o implícito risco que isso trás consigo, sobretudo se o trabalho de adaptação é insuficiente para estruturar um discurso teatral em que se privilegie as linguagens da nova obra resultante do trabalho da adaptação.

\section{Cinco grupos em um lugar de honra}

Não é por acaso que, tanto a nível nacional como internacional, comecem a se reiterar alguns destes grupos que propuseram uma nova estética da teatralidade. É o que o pesquisador chileno Alfonso de Toro chama uma "estética posmoderna":

O "novo" radica na tomada de consciência do teatrista como operário de espetáculos, como pedreiro de signos, como visualizador de gestos e não como produtor de textos literários para ser representados (...) $O$ "novo" se origina na radical concepção do teatro como gestualidade (...) O "novo" se encontra na revolução e subversão da linguagem, da cenografia, do papel do ator, isto é, do conceito de teatro. (S/D) ${ }^{3}$

Os cinco grupos que mencionaremos a continuação sintetizam, no seu trabalho, o sistema teatral imperante no período. Em todo caso, é importante assinalar que na década de 90 foram se formando outros coletivos (com uma ou duas peças estreadas), que constituíram, posteriormente, a "geração do ano 2000", frente à qual ainda existe pouca perspectiva histórica para dimensionar o valor de seu trabalho. No entanto, pode-se dizer que se percebe na produção dessa geração contatos com a idéia do cinematográfico, e a ativa presença do musical na cena, a desmitificação temática e abordagem visual das montagens.

\section{Teatro Fin de Siglo}

Dirigido por Ramón Griffero funcionou - em uma primeira instância - entre 1983 e 1989, fundamentalmente em um espaço marginal, como o foi a sala El Trolley, na rua San Martín (bairro de hotéis clandestinos e prostitutas). De sua produção ressalta a trilogia dramática do próprio Griffero: Historias Criação teatral no Chile nos últimos vinte. Eduardo Guerrero.

Dezembro 2007 - № 9 
de un galpón abandonado (1984), Cinema Utoppia (1985) e La morgue (1986), formando um todo representativo na reestruturação constante da linguagem teatral, na necessidade de criar novas formas de representação que permitissem dar, à cena, força e mágica. Em relação com estas três peças, Piña enfatiza:

Um dos diretores dramaturgos mais significativos neste periodo (década de 80) é Ramón Griffero, quem através de montagens como Historias de un galpón abandonado, Cinema Utoppia e La morgue, potencia os espaços visuais, sugere atmosferas de pesadelo e terror, e apela ao campo sensivel do espectador libertando-o da razão como unico fator para compreender um espetáculo. A ambigüidade, os ambientes indefinidos, as referências simbólicas ou poéticas e em geral o enriquecimento do mundo cênico, serviram para abrir um universo de significados que despertaram em um público, sobre tudo juvenil, outras ressonâncias. $(\mathrm{S} / \mathrm{D})^{4}$

Depois de haver estudado sociologia na Universidad de Chile, em outubro de 1973 Ramón Griffero partiu rumo à Inglaterra, onde continuou seus estudos. Anos depois entrou na Escola de Cinema de Bruxelas e, posteriormente, no Centro de Estudos Teatrais de Lovaina. Em 1981 surgiu sua primeira peça dramática, escrita em francês: Ópera para un naufragio. Nela visualizam-se posteriores preocupações de Griffero, muito presentes, por exemplo, em Cinema Utoppia. Seu segundo trabalho foi Altazor Equinoccio, em 1982. Reiterou seu interesse pela transformação do espaço e pelo uso de uma poética afim com seu ideário estético. Em um nível metafórico, existem nestes trabalhos referências ao sistema repressivo que imperava no Chile naqueles momentos.

Neste mesmo ano regressa ao Chile. Trazendo consigo uma valiosa experiência européia em benefício não somente do seu próprio desenvolvimento dramatúrgico mas, fundamentalmente, do teatro chileno, já que no terreno do estrito rigor de sua modalidade cênica ("posmoderna") abriu novas perspectivas de aproximação na busca de linguagens cênicas ainda não exploradas rigorosamente. A partir desse momento e, até a atualidade, estreou as seguintes peças: Recuerdos del hombre con su tortuga (1983), Historias de un galpón abandonado (1984), Cinema Utoppia (1985), La morgue (1986), Fotosintesis porno (1987), Viva la República (1989), Extasis o las sendas de la santidad(1994), Río abajo (1995), Sebastopol (1998), algumas das quais foram re-estreadas em uma nova etapa do coletivo.

O teatro de Ramón Griffero é um teatro de imagens, ainda que estas finalmente estejam apoiadas na palavra; por sua vez, um teatro que está em contínua preocupação por transgredir sistemas lingüísticos que vão perdendo força expressiva por causa, muitas vezes, de um uso superficial e reiterativo;

${ }^{4}$ Vid. Juan Andrés Piña: Modos y temas del teatro chileno: la voz de los 80. Mimeografiado. 
um teatro de luz e sombra, de sensações, de conscientes alterações espaciais e temporais; um teatro que deseja experimentar e encontrar uma nova linguagem cênica que dê conta, em sua plenitude, das peculiares indagações do dramaturgo ante o fenômeno teatral, considerando a globalidade da representação e a multiplicidade de signos que participam no jogo do palco. Em síntese, nesta oposição entre estética do texto/ estética da forma, o texto é um "pré-texto" para sustentar uma ou várias idéias articuladas em uma sucessão de imagens e símbolos com diversas possibilidades de leitura; neste sentido, o espectador tem uma importante função que cumprir, no nível imaginativo, no desvelamento textual.

Por isto mesmo, na hora de buscar referentes concretos nos trabalhos teatrais de Ramón Griffero, é inevitável mencionar a três grandes renovadores teatrais do Século XX, como o francês Antonin Artaud, o polonês Tadeusz Kantor e o norte americano Robert Wilson. São os mais genuínos representantes de um teatro cujo lema poderia ser formulado nos termos de "todo para olhar". Além disso, existe também uma linguagem plástica, sombras retomadas, fantasmas da memória. Por exemplo, em uma peça como Que explodam os artistas, de Kantor, encontramos elementos facilmente identificáveis no teatro de Ramón Griffero: movimentos entrecortados, sistema repetitivo que duplica ou triplica os efeitos, elegância plástica e beleza teatral.

O teatro de Ramón Griffero se insere - em um plano continental dentro dos espetáculos baseados no predomínio da imagem sobre a palavra. Desta maneira, apela a um espectador criativo que, através de suas possíveis leituras, estará dando as reais significações a uma representação onde o coreográfico, o plástico, o gestual, o mágico, o cotidiano, formam um todo único e insubstituível.

\section{Teatro del Silencio}

A companhia Teatro del Silencio foi criada em Santiago em dezembro de 1989, por Mauricio Celedón. Previamente, Celedón estudou na Academia de Mimos do Teatro Petropol (1975), incorporando-se à Compañía de Mimos em 1978 e participando em todas as montagens até 1980; logo, foi para Madri e ingressou no Teatro Lejanía, grupo com o qual visitou pequenas cidades espanholas com uma espécie de teatro de rua (deste período é sua peça Perseo, baseada no mito grego); pouco tempo depois, viajou a Paris e se relacionou diretamente com Etienne Decroux (pai da pantomima contemporânea) e Marcel Marceau. Desta maneira, com estes antecedentes e a direção de seus mimodramas Barrer, barrer hasta barrerlos (1986) e Gargantúa (1987), se iniciou uma nova etapa no seu desenvolvimento artístico com o Teatro del Silencio. 
Sob a direção de Mauricio Celedón, a companhia estreou o mimodrama de rua barroco Transfusión em janeiro de 1990 em diversos lugares públicos da cidade; dividido em cinco atos - cada um representa uma etapa da história das grandes migrações que povoaram a América Latina -, a fábula se centra nas aventuras de um hospital ambulante que vai às praças e aos parques, no qual se atendem pacientes que contam seus sonhos, enquanto esperam curarse. Por sua própria modalidade e proposta cênica, aparecem personagens arquetípicas, situações simbólicas, uma linguagem coreográfico-dramática apoiada no musical, com uma cenografia móvel sintetizada na presença de carros de mão (multifuncionais).

Posteriormente, com três peças - Ocho horas (1991), Malasangre (1991) e Taca-taca mon amour (1993) - o grupo alcança uma transcendência tanto nacional como internacional, que reafirmam a importância do trabalho de Mauricio Celedón. Se nessa heróica saga dos anônimos chamada Ocho horas (inspirada no dia internacional do trabalho) utilizam uma energia poucas vezes vislumbrada nos nossos palcos, é em Malasangre - uma homenagem ao poeta francês Arthur Rimbaud - onde alcançam elaborar um espetáculo de uma exuberante criatividade, naquilo que Griffero chamou "a dramaturgia

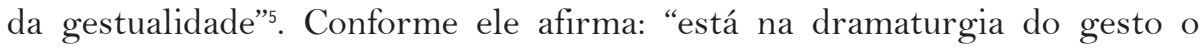
que imprime a marca pessoal do trabalho do Teatro del Silencio, a busca da gestualidade específica desta montagem, concebida dentro do envoltório de formas pré-burguesas. É neste ponto de busca de hieróglifos gestuais onde o caminho de ruptura com o eminentemente literal do narrativo mostra sua maior personalidade e riqueza, e entrega uma sub-textualidade requerida, ultrapassando o princípio das técnicas originárias, fazendo de Malasangre uma montagem destacada." ${ }^{\prime 6}$ Através de quatro etapas bem delimitadas da vida de Rimbaud, assistimos a uma aventura na qual o colorido, o movimento, a música, a coreografia, o figurino, o trabalho do ator, conformam sistemas sígnicos de uma riqueza inigualável. É um teatro de indagação no gestual, intuitivo, com um certo caráter antropológico, dentro de uma atmosfera expressionista. Segundo seu diretor, "é a poesia de Rimbaud realizada com o silêncio".

Quem segue a trajetória do Teatro del Silencio, encontra no mimodrama musical Taca-taca mon amour muitos elementos de suas anteriores produções, o que se materializa na busca desse teatro gestual, expressionista, adquirindo as diversas linguagens da encenação uma dinâmica própria para enfatizar com maior força as temáticas da história; para o pesquisador Sergio Pereira,"desde o ponto de vista dos códigos que sustentam a proposta de Celedón, a natureza gestual do espetáculo ativa de preferência aqueles códigos mistos como o proxêmico (relações espaciais das personagens), o quinestésico (postura corporal, gestos, expressões faciais) e alguns componentes para-lingüísticos (ruídos, expressões guturais, gritos, lamentos)."7

${ }^{5}$ Vid. Ramón Griffero: Radiografía de una dramaturgia, en: Revista Apuntes, Santiago de Chile, No.103 (Primavera 1991-Otoño 1992:

96).

${ }^{6}$ Vid. Ramón Griffero: Radiografía de una dramaturgia, Op.cit.,
${ }^{7}$ Sergio Pereira Poza: El "Taca taca" de Celedón, en: La Epoca, Santiago de Chile (5 de octubre de 1993)

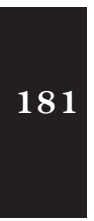


Assim, gestos, movimentos, maquiagens, iluminação projeto cenográfico, figurino, música, coreografia, criam uma chamativa teatralidade, uma poética no espaço, com um incessante movimento cênico, reforçando a presença de personagens intimamente vinculados a uma história na qual a violência, os signos do poder, do autoritarismo, se transformam em verdadeiros sintomas de degradação da espécie humana. De fundo, um esboço de poesia, da humanidade, de pensar científico, de racionalidade. Neste contexto, são plenamente reconhecíveis personagens como a rainha Vitória, Einstein, Stalin, Lênin, Hitler, Freud, Churchill e outros.

No último tempo, com distintos integrantes, o Teatro del Silencio se aproximou da França, visitando de forma esporádica nosso país, como novos espetáculos (por exemplo, Alice underground) que reforçam sua particular poética.

\section{Gran Circo Teatro}

Sob responsabilidade de Andrés Pérez, um dos diretores de maior criatividade do nosso meio (falecido em 2002), o Gran Circo Teatro estreou, entre seus espetáculos, La negra Ester (1988), El gran circo de Chile (1990), Ricardo II (1992), (1992), Popol-Vuh (1992), La consagración de la pobreza (1995), La huida (2001), De sirenas y rameras (2004), esta última dirigida por Rosa Ramírez e na qual fica em evidência a falta do mestre. Pérez trouxe ao Chile sua experiência adquirida na França, incorporando em sua proposta cênica a Comedia dell' Arte, as técnicas orientais, o trabalho da maquiagem (conceito de máscara), entre outros elementos. Das técnicas orientais, extraiu o misticismo no que se refere à preparação do ator, ao que agregava um exaustivo trabalho corporal acrobático.

De seus espetáculos, não cabe dúvidas de que La negra Ester (décimas de Roberto Parra) deve ser considerado como um dos mais significativos do teatro chileno dos últimos tempos, pois injetou vitalidade à nossa cena. Quando em dezembro de 1988 este espetáculo estreou na localidade de Puente Alto, ninguém suspeitou as ressonâncias - não somente teatrais ou artísticas, mas fundamentalmente sociais - que teria a mencionada representação. Depois, em pouco tempo, exatamente nos meses de janeiro e fevereiro de 1989, o morro Santa Lucía de Santiago foi palco de uma efervescência poucas vezes vista em torno a eventos culturais.

A história dos amores de Roberto Parra com a negra Ester, aquela prostituta do porto de San Antonio, é na realidade um mero pretexto para que os atores possam dar liberdade, com grande rigor, a uma criatividade 
descontrolada, apoiada pelas múltiplas linguagens cênicas. Em essência, La negra Ester é uma homenagem à poesia, ao teatro, à vida. É a metáfora que faz sonhar e suspirar; é a metáfora da palavra e o silêncio.

Em relação com os "dois Shakespeare imaginados pelo Gran Circo Teatro: Ricardo II e Noche de Reyes”, existe um referência no trabalho do grupo dos postulados do Theatre du Soleil, já que Andrés Pérez participou do Ciclo Shakespeare dirigido por Arianne Mnouchkine e, mais ainda, esteve durante vários anos trabalhando nesta companhia francesa, o que significou tanto uma contribuição pessoal como uma consolidação dos postulados no seu coletivo nacional.

Em sua última montagem, La huida, Pérez desvelou ao espectador sua condição homossexual, e junto a ela a discriminação e perseguição de que tinha sido vítima por parte de grupos conservadores e militares de nosso país; introduz o vídeo e a projeção de fotografias com o fim de mostrar, por uma parte, o contexto social, político e cultural do Chile da década de 20 e, por outra, desvelar o horror do castigo imposto a estes grupos discriminados.

Sem dúvida, se tratava de um espetáculo muito diferente do que tinha sido a proposta de Andrés Pérez, enquanto à valorização do popular e do festivo, e a inclusão de elementos circenses. Esta é uma peça intimista, uma espécie de tragédia contemporânea, com momentos de verdadeira violência. É o instante do despojo, de dar conta na cena de uma marginalidade que vem de seu ser gay e onde "entrega sua máscara” (máscara interior).

\section{La Troppa}

Está conformado por Jaime Lorca, Juan Carlos Zagal e Laura Pizarro, os três atores formados na Escuela de Teatro de la Universidad Católica. Em seus quase vinte anos de existência como grupo (faz alguns meses, anunciaram sua dissolução), em um trabalho de caráter coletivo, estrearam El santo patrono (1987), Salmón vudú (1988), Rap del Quijote (1989), Pinocchio (1990), Lobo (1992), Viaje al centro de la tierra (1995), Gemelos (1999), Jesús Betz (2003).

Em El santo patrono utilizava diversos elementos cenográficos que vão transformando no transcurso da peça; alem de cordas, pernas-de-pau, máscaras e cubos que ajudam a criar a atmosfera da história milagrosa da imagem de um santo. Em Salmón vudú ("Salmón, agonías y sueños”), nos encontramos com a busca de "impossíveis possíveis"; assim, elementos rítmicos, humorísticos, os diversos papéis assumidos, a capacidade de estabelecer o jogo cênico, 
possibilitam a necessária interação com um público chamado a desvelar intencionalidades que vão além do mero pretexto de contar uma história. $E l$ Rap del Quijote é uma personalíssima versão de Dom Quixote de la Mancha, destinada a um público juvenil.

Em sua máxima globalidade, a montagem de Pinocchio é de excepcional valor, o que o coloca ao lado das produções mais destacadas do teatro infantil no Chile. Às criativas interpretações dos três integrantes da companhia, deve-se somar a interessante proposta cênica, na qual o trabalho da imagem se priorizava sobre o próprio texto, em um jogo constante de planos, de enfoques, de aproximações. Este ritmo imposto e a inter-relação com a linguagem cinematográfica, criavam as condições adequadas para que a história se valorizasse desde diferentes perspectivas e pudesse ter leituras do mundo infantil e adulto. $\mathrm{O}$ elemento musical agregava à representação um caráter muito especial, eficaz complementando as outras linguagens e, por sua vez, com uma manifesta vitalidade expressiva. Finalmente, tanto o figurino como a cenografia, também apoiavam com acerto este criativo espetáculo.

A adaptação teatral do romance Viaje al centro de la tierra - uma das geniais obras de fantasia de Julio Verne -, não somente passou a ser uma válida homenagem ao cumprir-se os noventa anos do falecimento do visionário escritor francês em 1995, como também reafirmou a solidez do grupo e sua capacidade para transformar o palco em um espaço cênico cheio de imaginação e sonho. Como em suas realizações anteriores, desde uma perspectiva temática, voltamos a nos encontrar com o motivo da viagem como eixo estruturante. De fato, durante quase uma hora e meia de espetáculo, seguimos a "enlouquecida e delirante aventura" do professor Lidenbrock e de seu sobrinho Axel, que descobrem em um antigo manuscrito uma revelação transcendental: por uma das chaminés do vulcão Sneffels, se penetra ao centro da terra.

De princípio ao fim a montagem de La Troppa se caracteriza pelo engenho, criatividade, humor, empatia com o espectador, soltura, utilizando constantemente as linguagens da teatralidade em apoio do texto adaptado. Desta maneira, esta proposição lúdica vai acompanhada de um constante apoio musical, de diversos efeitos e sons, de objetos de cena, de uma antiga locomotiva com um sentido funcional, transformando-se, finalmente, em uma espécie de labirinto onde ocorrem as situações dramáticas. Tudo isto se vê reforçado pelo desempenho atoral de Jaime Lorca e Juan Carlos Zagal, com uma graça e recursos expressivos para comprometer ao espectador na história narrada.

O sucesso internacional de La Troppa não é fruto do acaso. Ao contrário, é o resultado de um trabalho sério, profissional, com uma estética definida e com uma especial desenvoltura para abordar o objeto artístico. Através dos 
anos, o coletivo foi adquirindo uma maior hierarquia em suas propostas, o que ficou evidente na montagem de Gemelos, adaptação teatral do romance El gran cuaderno, da escritora húngara Agota Kristof, cuja história nos remete à relação de uns gêmeos com sua avó, depois de que a mãe dos jovens os abandona e o pai vai para o campo de batalha. A encenação é surpreendente: em uma cenografia que se assemelha ao de um guignol (pequeno teatro do mundo), somos testemunhas de um conto cheio de humanidade e terror com o condimento de uma exagerada atuação que apóia o desenvolvimento da trama. Também se entrecruzam no palco múltiplas linguagens teatrais, desde a música, a iluminação, os contínuos efeitos e sons, o cinematográfico com seus diversos planos, o colorido, as imagens, os truques cenotécnicos.

\section{Teatro La Memória}

Em dezembro de 1987, com a estréia de sua primeira peça, Estación Pajaritos, Alfredo Castro começa sua atividade no Teatro La Memoria, em torno da idéia de buscar uma expressão estética que fosse mais própria e atraente. Sobre isso ele dizia: "A companhia se chama Teatro La Memoria, porque estamos trabalhando com o inconsciente coletivo. Chile é um povo que não tem memória; cada um se remete a suas próprias ações, quando há múltiplas possibilidades em seu entorno."

Em seus seis anos de funcionamento estrearam também os seguintes espetáculos: El paseo de Buster Keaton (1988), La tierra no es redonda (1989), La

${ }^{8}$ Alfredo Castro: Historia del grupo, en: Programa a Estación Pajaritos manzana de Adán (1990), Historia de la sangre (1992) e Los días tuertos (1993). Neste trabalho, tanto como ator, mas prioritariamente como dramaturgo e como diretor, Alfredo Castro violentou os usuais cânones teatrais, propondo a aludida estética posmoderna da teatralidade.

Estreada em junho de 1990 em uma casa abandonada do Bairro Bellavista (uma forma de acentuar ainda mais a marginalidade), a montagem de La manzana de Adán se baseia no livro homônimo da jornalista Claudia Donoso e da fotógrafa Paz Errázuriz, com adaptação teatral de Alfredo Castro. Tem como pano de fundo a história de dois irmãos travestis, Keko/Pilar e Leo/Evelyn, "observados" pelo olho acusador da Mãe e, mais ainda pelo da sociedade.

Desta maneira, a partir do discurso das personagens, se configuram relações patéticas intensas, solidão, dor, que expõe - através de um linguagem descarnada e despojada - da intensidade das paixões. Além disso, se enfatiza estritamente o aspecto do testemunho, para assim provocar no espectador uma sensação de desamparo ainda maior. 


\section{Urdimento}

`Vid. Verónica GarcíaHuidobro (Primavera 91/0toño 92: 100).
Já em Historia de la sangre o ponto de partida é uma pesquisa sobre o testemunho como fonte de criação artística (pesquisa de testemunhos de criminais presos por homicídio passional). Isto dá lugar à estruturação de um texto (dramaturgia de Alfredo Castro) que, por sua vez, é outro ponto de arranque para reelaborar metaforicamente o material pesquisado. A esta somatória de mediações, deve-se agregar a aproximação do receptor/ espectador ante uma peça desta natureza, com todo o matiz de provocação que indiretamente subjaz cada "história de sangue".

O testemunho-base que orienta a direção da proposta é o de Rosa Faúndez, a vendedora de jornais que em 1923 esquartejou "seu homem"; a este testemunho, se somam outros cinco discursos, cada um dos quais perfila sua individualidade, mas em função do coletivo (monólogos que são diálogos, como em La manzana de Adán); desta forma, assistimos à história de muitos sangues, concretizada em seis momentos de imensurável dor. Nas palavras da diretora Verónica García-Huidobro, “o testemunho é utilizado como fonte de criação que ao ser reinterpretado artisticamente transcende o nível poético e simbólico aproximando o teatro à vida."

A direção de Alfredo Castro tem como premissa preencher o espaço cênico de múltiplos significados ("espaço de ausências"), para o qual se vale de toda linguagem capaz de ser articulada na encenação, seja esta o próprio trabalho atoral, o gesto, o movimento, a música, a iluminação, a cenografia, o figurino, entre outros.

Em geral, a função do resto dos sistemas sígnicos, é a de apoiar os motivos subjacentes do texto, através da sugestão e da evocação, motivos que têm relação com a presença do marginal, a subversão, as pegadas de cada sangue historiado, tudo o que está sutilmente coberto de nostalgia e ternura.

O teatro chileno contemporâneo tratou de configurar sua própria identidade. Problemas econômicos, escassez de salas, nulo apoio institucional e das empresas privadas, um público resistente a ficar em dia com as atuais experimentações cênicas, atores que se fecham em modelos das telenovelas, são alguns dos impedimentos que obstaculizam um real desenvolvimento da arte cênica no Chile. Mas, entre subdesenvolvimento e subdesenvolvimento (ou em vias de desenvolvimento, se preferem assim), seguem existindo tentativas válidas de configurar um teatro de relevância internacional. De uma ou outra forma, a existência destes cinco grupos permite valorizar esta significativa projeção artística. 


\section{Realidade atual}

Depois do aluvião criativo dos anos 80, no que se refere ao aparecimento de coletivos que "revolucionaram" a cena nacional, o panorama posterior é bastante pobre, tanto no que compete à criação de novos grupos como, fundamentalmente, ao estado da escritura cênica.

A respeito deste último aspecto, é necessário efetuar algumas observações pontuais. Em termos gerais, a geração de dramaturgos chilenos vinculados com a criação dos teatros universitários, como se assinalou anteriormente, se constituiu no principal referente dramatúrgico do nosso teatro. Eles ocuparam a atividade cênica dos anos 60 e muitos seguiram plenamente vigentes. Logo, nos anos 70, em plena ditadura militar, a criação coletiva se transformou na principal modalidade teatral e somente alguns dramaturgos isolados, de distintas formações e estrato social, emergiram no fim dos 80 .

O que aconteceu posteriormente? Muita euforia, mas uma pobreza abismal na escritura. Por exemplo, na década de 90, o único dramaturgo que manteve uma produção digna de destacar foi Benjamín Galemiri, autor de $E l$ coordinador, peça que logo foi estreada em Moscou. Além disso, surgiu muita escritura cênica absolutamente prescindível, com jovens escritores (a grande maioria provenientes do mesmo âmbito teatral, isto é, atores, diretores...) que, com apenas uma ou duas peças, muitas delas carentes de sólida construção dramática, de propostas interessantes de personagens, foram reconhecidos pela institucionalidade teatral chilena, o que soa como um exagero. Então, o que presenciamos nos últimos tempos, são tentativas de uma verdadeira dramaturgia, com temáticas auto-referentes, monólogos mais que diálogos e carentes de profundidade. Falta, no essencial, um discurso político, um olhar crítico, uma necessidade de transcendência. Vive-se a urgência e a superficialidade. Vive-se uma época de incerteza.

O afirmado anteriormente não quer dizer que, nos últimos tempos, não tenham aparecido novas peças nem novas montagens. Ao contrário. Há uma programação teatral que oferece - cada fim de semana - entre trinta a quarenta espetáculos, quantidade suspeita em um país sem uma sólida tradição teatral. Há um excesso de triunfalismo, que leva inclusive alguns a dizer que "Chile é um país de dramaturgos" como antes se dizia que era um "de poetas" em referência a nossos dois Prêmios Nobel de Literatura (Gabriela Mistral e Pablo Neruda). 
Outro aspecto de longa discussão se relaciona com a condição do dramaturgo. Isto é, o discurso existente na atualidade é que as peças teatrais têm que ser escritas por gente de teatro, e não por gente proveniente de outras áreas. É curioso. Mas, sem querer ser reiterativo, as mais sólidas peças de teatro foram escritas por Díaz (arquiteto), Wolff (engenheiro químico), Heiremans (médico), Vodanovic (advogado), etc. Indiscutivelmente, em uma encenação, o texto é uma linguagem mais (significativo, sem dúvida), mas a conjunção das chamadas linguagens da teatralidade dará a este sua real consistência cênica.

Um dos postulados programáticos da criação dos teatros universitários, na década dos 40, foi a criação de escolas de teatro. Assim, no final da década e começo da seguinte, surgiram as duas escolas de teatro mais antigas do nosso país, a da Universidad Católica e a da Universidad de Chile. Durante muitos anos, estas foram as únicas na capital. Mas, a partir dos anos 90, começaram a proliferar muitas escolas de teatro particulares (entre as que nos encontramos), mais de trinta na totalidade. Isto, de alguma forma, se vincula com uma mudança na mentalidade enquanto a uma maior aceitação da sociedade pelo estudo dos jovens de carreiras artísticas. Constitui-se em uma moda. Isto é bom, mas também ruim. Incrementa a atividade, pois existem mais oportunidades, mas começa a primar o quantitativo sobre o qualitativo. Parece ser muito mais fácil agora ter o título de ator e existir menos dificuldades no caminho. Ademais, o fenômeno da televisão tem algo que ver no assunto, pois a "tentação" de aparecer em alguma série televisiva não deixa de entusiasmar aos jovens.

É necessário pensar o teatro, ou repensá-lo. Pessoalmente, opino que esta modalidade artística possui uma transcendência que não condiz com a realidade atual. É preciso renascer da crise. O teatro está passando, como em outras épocas, sua particular crise. O comercial se apodera dos palcos. O comercial ruim. Em todo caso, não é hora de buscar culpados. É hora de que o teatro recupere, pelo menos no Chile, seu caminho e sua dignidade. Os deuses gregos nos observam do Olimpo. 


\section{NORMAS PARA PUBLICAÇÃo DE ARTIGOS}

1) Artigos - mínimo de 8 e máximo de 12 laudas. Resenhas de livros - mínimo de 3 e máximo de 4 laudas. Digitação em tipologia 12, Times New Roman, espaçamento normal, Word para Windows (ou compatível), limite de 5.700 caracteres com espaços por lauda;

2) Solicita-se clareza e objetividade nos títulos;

3) As notas devem ser formatadas em algarismos arábicos, apresentadas no rodapé da página. A bibliografia deve ser acrescentadaimediatamente após as notas, obedecendo ao seguinte padrão: SOBRENOME, Nome, Título (tradutor), Local, Editora, Ano, páginas referidas (ex: 13-16). Para periódicos e jornais: SOBRENOME, Nome, Artigo/Reportagem, Periódico ou Jornal, n ${ }^{\circ} \mathrm{V}$ (tradutor), Local, Editora, Ano ou Data, páginas referidas. Periódicos não devem ter títulos abreviados;

4) Para indicações de obras no corpo do texto ou final da citação: SOBRENOME, Ano: número da página. Para quaisquer outras normas, seguir o padrão ABNT vigente;

5) No corpo do texto, usar a primeira letra maiúscula e toda(s) a(s) palavra(s) em itálico para nomear títulos de peças, óperas, livros, títulos e obras em geral;

6) As colaborações devem incluir uma brevíssima apresentação do autor, visando situar o leitor, de no máximo 3 linhas;

7) À parte, o colaborador deve enviar uma autorização para publicação. Caso inclua fotos, desenhos ou outros materiais gráficos da autoria de terceiros, é indispensável o aceito dos mesmos assim como uma legenda de identificação; 
Urdimento

8) $\mathrm{O}$ conjunto destinado à publicação deve ser encaminhado em duas cópias impressas, uma em CD e outra para o e-mail urdimento@udesc. br aos cuidados da revista, até o prazo do fechamento.

Endereço para correspondência e envio de colaborações:

\section{Revista Urdimento}

Programa de Pós-Graduação em Teatro - UDESC

Av. Madre Benvenuta, 1.907 - Itacorubi

88.035-001 - Florianópolis - SC

E-mail: urdimento@udesc.br 
Realização:

\section{PPG Teatro}

Programa de Pós-Graduação em Teatro

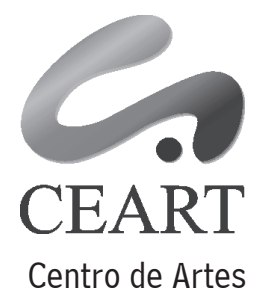


Diagramação Editorial

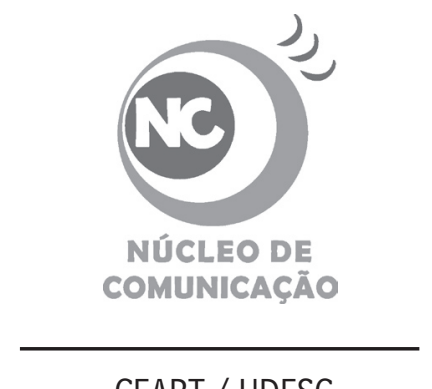

CEART / UDESC

Este projeto editorial foi criado eletronicamente utilizando o software Adobe In Design CS3. As famílias tipográficas Bell MT e BellCent são utilizadas em toda esta revista. 